\title{
Effect of Minor Sn Additions on the Formation and Properties of TiCuZrPd Bulk Glassy Alloy
}

\author{
Shengli Zhu*, Guoqiang Xie, Fengxiang Qin, Xinmin Wang and Akihisa Inoue \\ Institute for Materials Research, Tohoku University, Sendai 980-8577, Japan
}

The minor addition is fundamental to controlling the formation, manufacture and properties of metallic materials by controlling nucleation during solidification. In the present work, we investigated the effect of minor addition of Sn on glass-forming ability, thermal stability and mechanical property of TiZrCuPd bulk glassy alloy system. The substitution of $\mathrm{Cu}$ by $2 \% \mathrm{Sn}$ improves the glass-forming ability significantly. The $\mathrm{Ti}_{40} \mathrm{Zr}_{10} \mathrm{Cu}_{34} \mathrm{Pd}_{14} \mathrm{Sn}_{2}$ bulk glassy alloy rod with a diameter of $12 \mathrm{~mm}$ was fabricated by copper mold casting. The Ti ${ }_{40} \mathrm{Zr}_{10} \mathrm{Cu}_{34} \mathrm{Pd}_{14} \mathrm{Sn}_{2}$ bulk glassy alloy exhibits higher energy for crystallization activation $(334.3 \mathrm{~kJ} / \mathrm{mol})$. The addition of $2-4 \%$ Sn can enlarge the supercooled liquid region, indicating good thermal stability. TiZrCuPdSn bulk glassy alloys exhibit high compressive strength about $2000-2050 \mathrm{MPa}$. [doi:10.2320/matertrans.M2011281]

(Received September 8, 2011; Accepted December 22, 2011; Published February 15, 2012)

Keywords: bulk glassy alloy, biomaterials, minor addition, glass-forming ability

\section{Introduction}

Bulk glassy alloys exhibit high mechanical strength and good corrosion resistance which enable us to use as structural and functional materials. ${ }^{1-4)}$ Ti-based bulk glassy alloys are expected to be applied as biomaterials because of their excellent corrosion resistance, good biocompatibility, low Young's modulus and high recovery of strain $(>2 \%)$. Some of works have been made for Ti-based bulk glassy alloys, such as $\left.\left.\mathrm{Ti}-\mathrm{Ni}-\mathrm{Cu},{ }^{5}\right) \mathrm{Ti}-\mathrm{Ni}-\mathrm{Cu}-\mathrm{Co},{ }^{6}\right) \mathrm{Ti}-\mathrm{Cu}-\mathrm{Ni}-\mathrm{Sn},{ }^{7} \mathrm{Ti}-\mathrm{Zr}-$ $\mathrm{Cu}-\mathrm{Ni}^{8)}$ and others $\mathrm{Ti}-\mathrm{Be}-\mathrm{based}^{9}{ }^{9}$ systems. In our previous work, we have developed a $\mathrm{Ti}-\mathrm{Zr}-\mathrm{Cu}-\mathrm{Pd}$ bulk glassy alloy. The $\mathrm{Ti}-\mathrm{Zr}-\mathrm{Cu}-\mathrm{Pd}$ alloys exhibit high glass-forming ability (GFA), higher strength and lower Young's modulus. ${ }^{10)}$

The minor addition is fundamental to controlling the formation, manufacture and properties of materials because the nucleation of crystalline phases is relevant for all solidification and the minor addition is an effective way to control the nucleation. The minor addition technique was used in the bulk glassy alloy field to improve the GFA, thermal, mechanical and physical properties, or synthesis novel materials such as nano-materials, glassy matrix composite with improved properties. ${ }^{11)}$ Some minor elements had been used in Ti-based bulk glassy alloys. Only 1 at\% Si addition is effective in facilitating glass formation for the Tibased alloys, ${ }^{12,13)}$ and minor Si addition favors of enlarging the super liquid region (SCL). ${ }^{12,14)}$ Some metallic atoms, such as $\mathrm{Sn}$ and $\mathrm{Ni}$, are helpful in term of glass formation for Ti-based alloys ${ }^{15-18)}$ and $\mathrm{Sn}$ addition is also benefit in improving the thermal stability. ${ }^{18)}$ Kong reported that 1 at\% $\mathrm{Al}$ or $\mathrm{Si}$ addition would enhance the bending flexural strength of $\mathrm{Cu}-\mathrm{Ti}$ based bulk glass alloy. ${ }^{19)} \mathrm{Nb}$ addition in $\mathrm{Ti}-\mathrm{Cu}$ based bulk glassy alloy was reported as distinct plastic strain due to the precipitation of nano particles. $^{20)}$ In the present work, we investigate the effects of minor $\mathrm{Sn}$ addition on the GFA, thermal and mechanical properties of TiZrCuPd bulk glassy alloys.

*Corresponding author, E-mail: slzhu@imr.tohoku.ac.jp

\section{Experiments}

The master ingots of a series of TiZrCuPdSn alloys were prepared by arc-melting the pure elements with purities above $99.9 \%$ in a vacuum arc furnace with argon atmosphere. The alloy composition represents the nominal atomic percentage of the mixture. The ribbon samples with a cross section of $0.02 \times 2 \mathrm{~mm}^{2}$ were prepared by melting the master ingots, and ejecting through a nozzle onto a $\mathrm{Cu}$ wheel rotating with a surface velocity of $40 \mathrm{~m} \cdot \mathrm{s}^{-1}$. The rod samples were prepared from melting master ingot by casting into a copper mold with different diameters. Glassy structure was examined by X-ray diffraction (XRD, Rigaku RINT-Ultima, monochromatic $\mathrm{Cu} \mathrm{K} \alpha$ radiation). Thermal stability was evaluated by differential scanning calorimetry (DSC, TA DSC Q-100) with different heating rates and differential thermal analysis (DTA, TA SDT Q-600) with the heating rate of $0.33 \mathrm{~K} / \mathrm{s}$. Compressive tests were conducted by a mechanical testing machine (Shimadzu AG-X) under a strain rate of $5 \times 10^{-4} \mathrm{~s}^{-1}$. The compression samples were $2 \mathrm{~mm}$ in diameter and $4 \mathrm{~mm}$ in length.

\section{Results and Discussion}

Figures 1 and 2 shows the DSC and DTA curves of some TiZrCuPdSn glassy alloys. The glass transition temperature $\left(T_{\mathrm{g}}\right)$, crystallization temperature $\left(T_{\mathrm{x}}\right)$, onset melting temperature $\left(T_{\mathrm{m}}\right)$ and terminal melting temperature $\left(T_{1}\right)$ were marked in the figures. In the design of new bulk glassy alloys, it is vital for us to quantify and eventually predict relative GFA of different multicomponent alloy systems. Scientific efforts for searching proper GFA criterion for glassy alloys have been carried out. The reduced glass transition temperature $\left(T_{\mathrm{rg}}\right)$ defined as the ratio of $T_{\mathrm{g}}$ to $T_{1}$ has been successfully used to evaluate the GFA of various glassy alloys. The supercooled liquid (SCL) region, defined as the temperature interval $\Delta T_{\mathrm{x}}=T_{\mathrm{x}}-T_{\mathrm{g}}$, was also regarded as a useful parameter of GFA. ${ }^{21)}$ The other GFA parameters $\gamma=\frac{T_{\mathrm{x}}}{T_{\mathrm{g}}+T_{1}}$ and $\delta=\frac{T_{\mathrm{x}}}{T_{1}-T_{\mathrm{g}}}$ were also used to evaluate the GFA of a glassy alloy. ${ }^{22,23)} \mathrm{In}$ the present study, the $\mathrm{Sn}$ content dependences of $T_{\mathrm{rg}}, \Delta T_{\mathrm{x}}, \gamma$ 

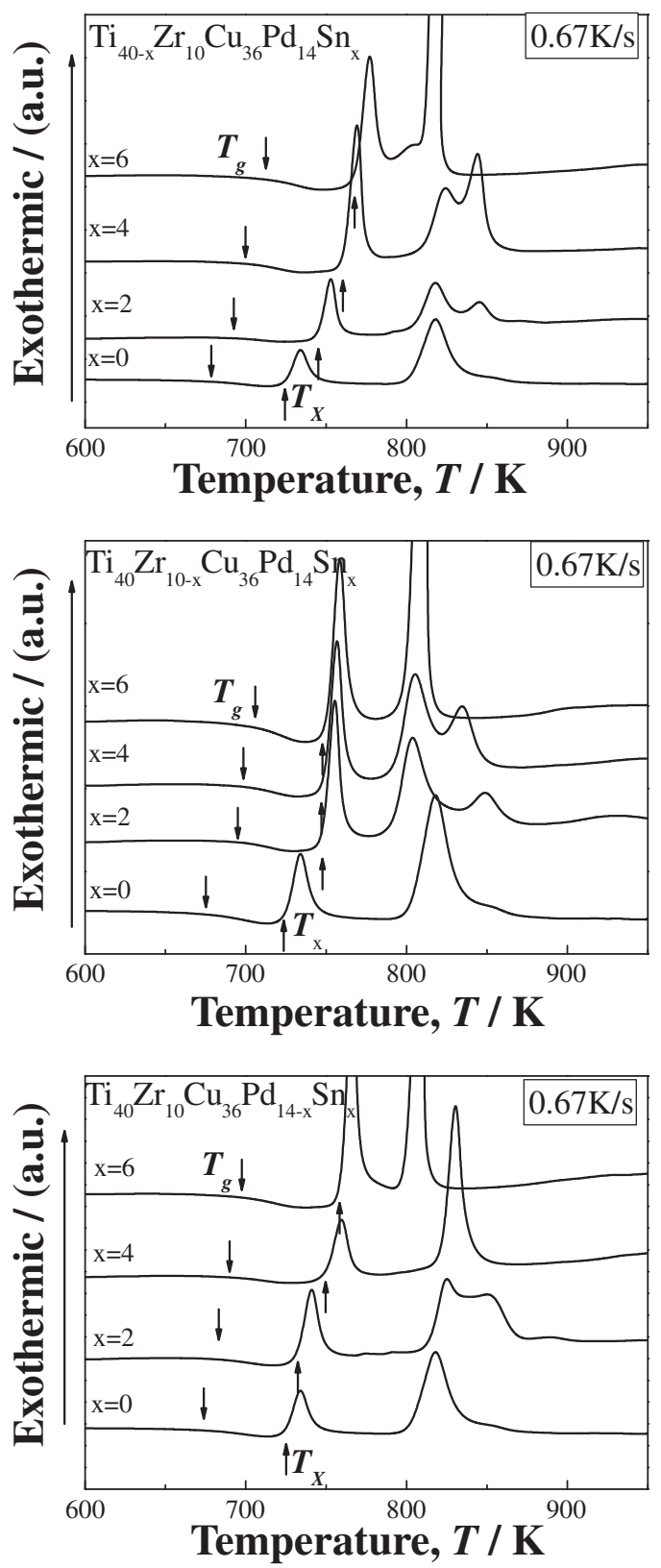

Fig. 1 DSC curves of TiZrCuPdSn glassy alloys.

and $\delta$ were shown in Fig. 3 to evaluate the GFA. The additions of $\mathrm{Sn}$ to replace any element can increase the $T_{\mathrm{g}}$. The substitutes of $\mathrm{Ti}, \mathrm{Cu}$ and $\mathrm{Pd}$ by $2 \% \mathrm{Sn}$ can decrease the $T_{1}$, while the substitute of $\mathrm{Zr}$ by $\mathrm{Sn}$ increases the $T_{1}$. The substitutes of $\mathrm{Cu}$ and $\mathrm{Ti}$ by $2-4 \% \mathrm{Sn}$ result in higher $T_{\mathrm{rg}}$, $\delta$ and $\gamma$, being supposed higher glass-forming ability. The addition of $2-4 \% \mathrm{Sn}$ to replace $\mathrm{Ti}, \mathrm{Cu}$ and $\mathrm{Pd}$ can enlarge the supercooled liquid region, being supposed higher thermal stability.

Figure 4 shows the XRD patterns of some TiZrCuPdSn rods prepared by copper mold casting. The addition of $2 \% \mathrm{Sn}$ can improve the GFA. A full glassy structure can be obtained for $\mathrm{Ti}_{40} \mathrm{Zr}_{10} \mathrm{Cu}_{34} \mathrm{Pd}_{14} \mathrm{Sn}_{2}$ rod with a diameter of $12 \mathrm{~mm}$ and $\mathrm{Ti}_{38} \mathrm{Zr}_{10} \mathrm{Cu}_{36} \mathrm{Pd}_{14} \mathrm{Sn}_{2}$ rods with a diameter of $10 \mathrm{~mm}$. The shiny contrast on the smooth outer surface was observed for the full glassy samples. Inset of Fig. 4 shows the outer surface of the $12 \mathrm{~mm} \mathrm{Ti}{ }_{40} \mathrm{Zr}_{10} \mathrm{Cu}_{34} \mathrm{Pd}_{14} \mathrm{Sn}_{2}$ rod. However, the XRD pattern of $\mathrm{Ti}_{40} \mathrm{Zr}_{10} \mathrm{Cu}_{34} \mathrm{Pd}_{14} \mathrm{Sn}_{2}$ alloy rod with a
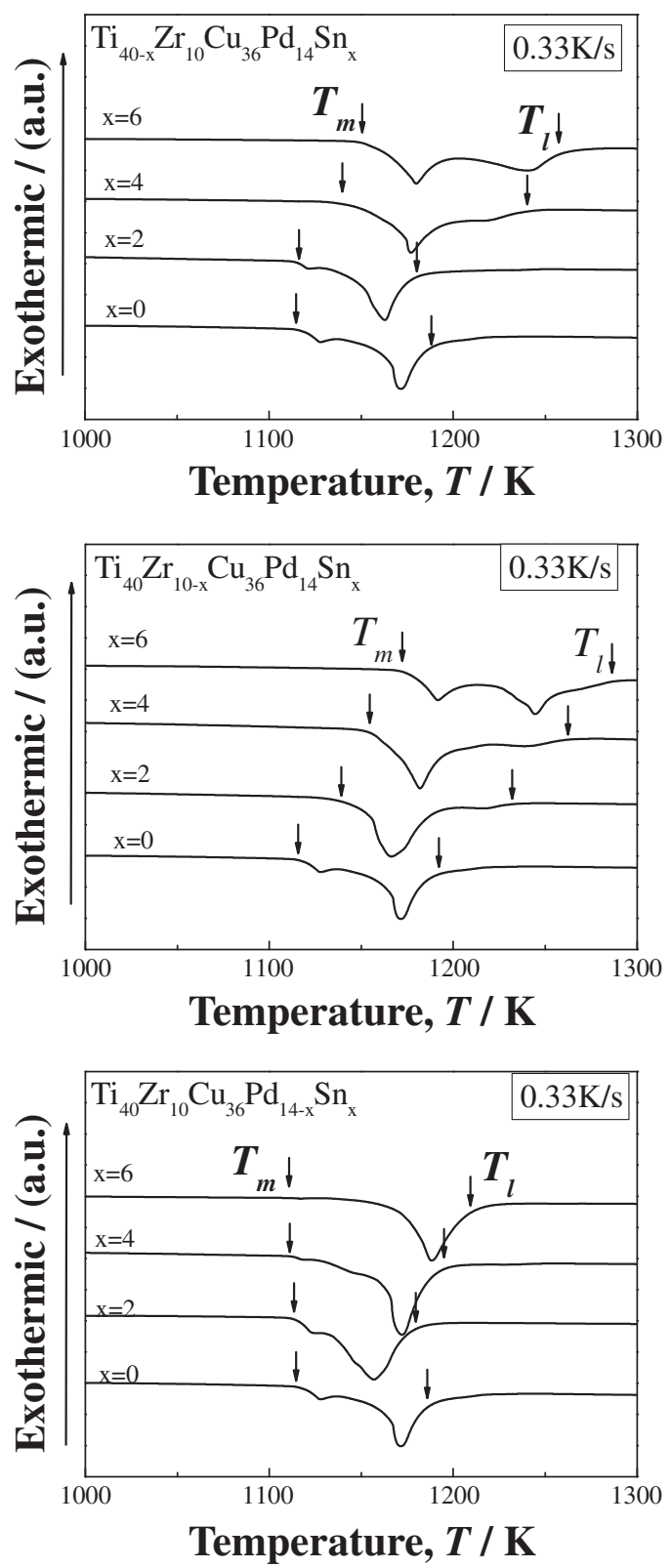

Fig. 2 DTA curves of TiZrCuPdSn glassy alloys.

diameter of $15 \mathrm{~mm}$ shows some crystallized phases which can be identified as $\mathrm{PdTi}_{2}, \mathrm{CuTi}$ and $\mathrm{Cu}_{8} \mathrm{Zr}_{3}$.

$\mathrm{Ti}-\mathrm{Zr}-\mathrm{Cu}-\mathrm{Pd}$ quaternary alloy system exhibits high GFA due to large atomic size mismatches of $\mathrm{Ti}, \mathrm{Zr}, \mathrm{Cu}$ and $\mathrm{Pd}$ elements, difficulty in the precipitation of stable $\mathrm{ZrTiCu}_{2}$ compound phase from liquid and the negative mixing enthalpies of $\mathrm{Pd}$ with other constituent elements. ${ }^{10)}$ The GFA of bulk glassy alloys is related to two aspects: liquid phase stability and kinetics of forming competing crystalline phases. Either increasing the liquid phase stability or suppressing crystalline phase formation can increase the GFA. In the present work, with the addition of Sn, the GFA is improved. Some reasons should be considered. First, the $\mathrm{Sn}-\mathrm{Ti}, \mathrm{Sn}-\mathrm{Zr}$ and $\mathrm{Sn}-\mathrm{Pd}$ pairs exhibit negative heat of mixing $(-21,-43$ and $-34 \mathrm{~kJ} / \mathrm{mol}$, respectively). In a purely thermodynamic consideration, the substantially negative heat of mixing would result in a deeply depressed free energy curve of the undercooled liquid and, hence in small free 


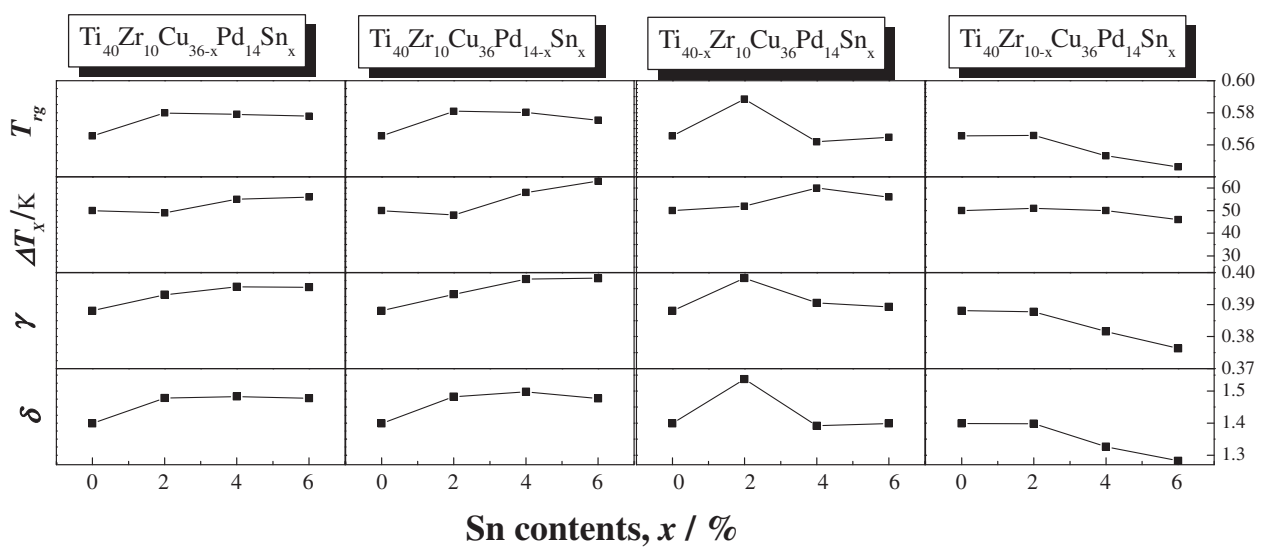

Fig. 3 GFA evaluation parameters of TiZrCuPdSn bulk glassy alloys.

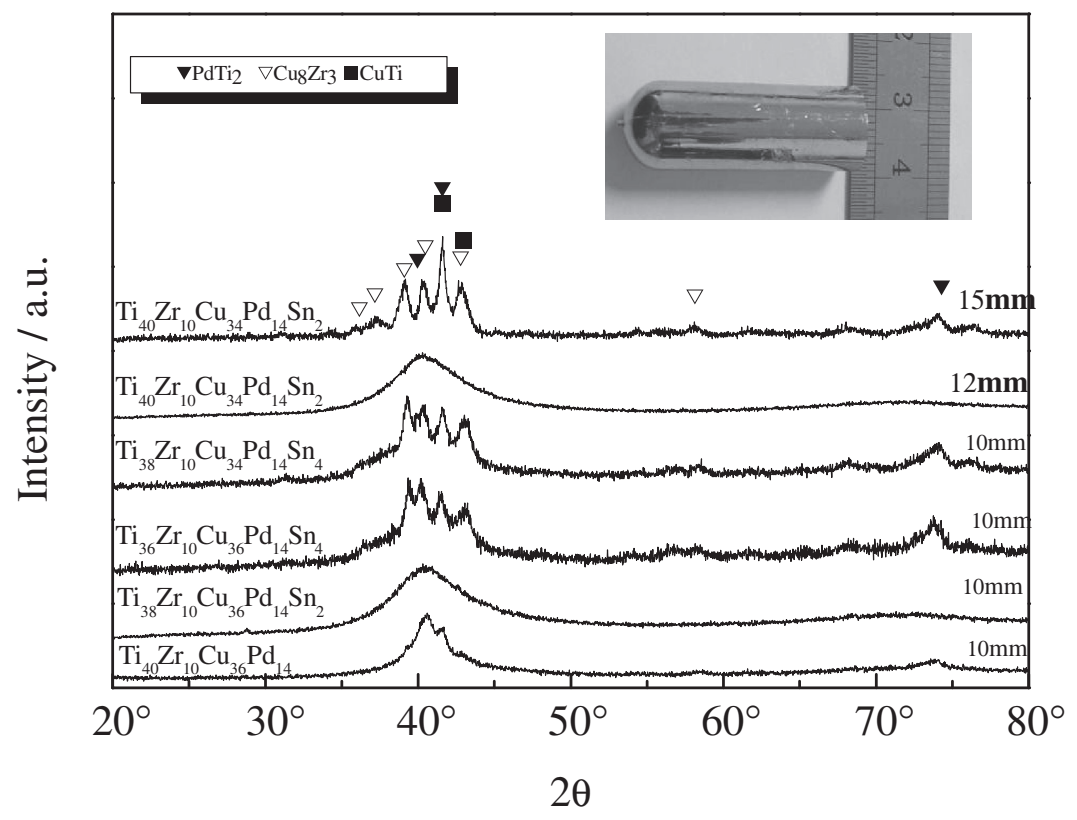

Fig. 4 XRD patterns of TiZrCuPdSn bulk glassy alloys.

energy driving forces for crystallization. ${ }^{24)}$ This would lead to a wide composition range for metallic glass formation in a given system. Hence, the addition of Sn would suppress the crystalline phase formation. Second, the large atomic size differences between $\mathrm{Sn}(0.14 \mathrm{~nm})$ and $\mathrm{Zr}$ or $\mathrm{Cu}(0.16$ and $0.128 \mathrm{~nm}$, respectively) should destabilize the primary crystallized phases in the melt alloy by introducing the complexity and size mismatch of unit cell. Also, the addition of $\mathrm{Sn}$ increases the complexities in element species. The majority of BMG compositions are associated with a complex multicomponent chemistry. The large complexities in element species and atomic sizes are believed to significantly frustrate the crystallization tendency of the undercooled liquid and hence to favor BMG formation at slow cooling. ${ }^{25)}$ In addition, the absolute value of mixing heats between the larger atoms $\mathrm{Sn}$ and $\mathrm{Zr}$ is relatively large. Hence, $\mathrm{Sn}$ and $\mathrm{Zr}$ have the tendency to get together, which would result in increasing the difficulty of inter-atomic diffusion. Then the stability of the undercooled melt and the supercooled liquid would be enhanced. Furthermore, either GFA or thermal stability is improved.
The Kissinger method is used to determine the kinetic constants of phase transformation obtained using a DSC. The details of Kissinger method was reported in Ref. 26). The Kissinger method can be described briefly as the following equation:

$$
-\frac{E_{\mathrm{p}}}{R}=\mathrm{d}\left(\ln \frac{\beta}{T_{\mathrm{p}}^{2}}\right) / \mathrm{d}\left(\frac{1}{T_{\mathrm{p}}}\right)
$$

where $\beta$ is the heating rate, $T_{\mathrm{p}}$ is the first peak temperature, $R$ is gas constant and $E_{\mathrm{p}}$ is the activation energy. The plot of $\ln \left(\frac{\beta}{T_{\mathrm{p}}^{2}}\right)$ versus $\frac{1}{T_{\mathrm{p}}}$ has a linear shape, which allows $E_{\mathrm{p}}$ to be calculated using the slope of the linear fit. Figure 5 shows the DSC curves measured under different heating rate and the Kissinger's plot for the $\mathrm{Ti}_{40} \mathrm{Zr}_{10} \mathrm{Cu}_{34} \mathrm{Pd}_{14} \mathrm{Sn}_{2}$ glassy alloy. The value of activation energy $E_{\mathrm{p}}$ was calculated as $334.3 \mathrm{~kJ} / \mathrm{mol}$ which was higher than that of the TiZrCuPd glassy alloy without $\mathrm{Sn}$ addition $(287.6 \mathrm{~kJ} / \mathrm{mol}) .{ }^{14)}$ This indicates the improvement of thermal stability due to the $\mathrm{Sn}$ addition. The $\mathrm{TiCu}$ phase is considered as preferable crystallized phase for the Ti-Cu-rich bulk glassy alloys. Due to very low solubility of $\mathrm{Sn}$ to $\mathrm{TiCu}$ phase, the precipitation of $\mathrm{TiCu}$ phase requires 

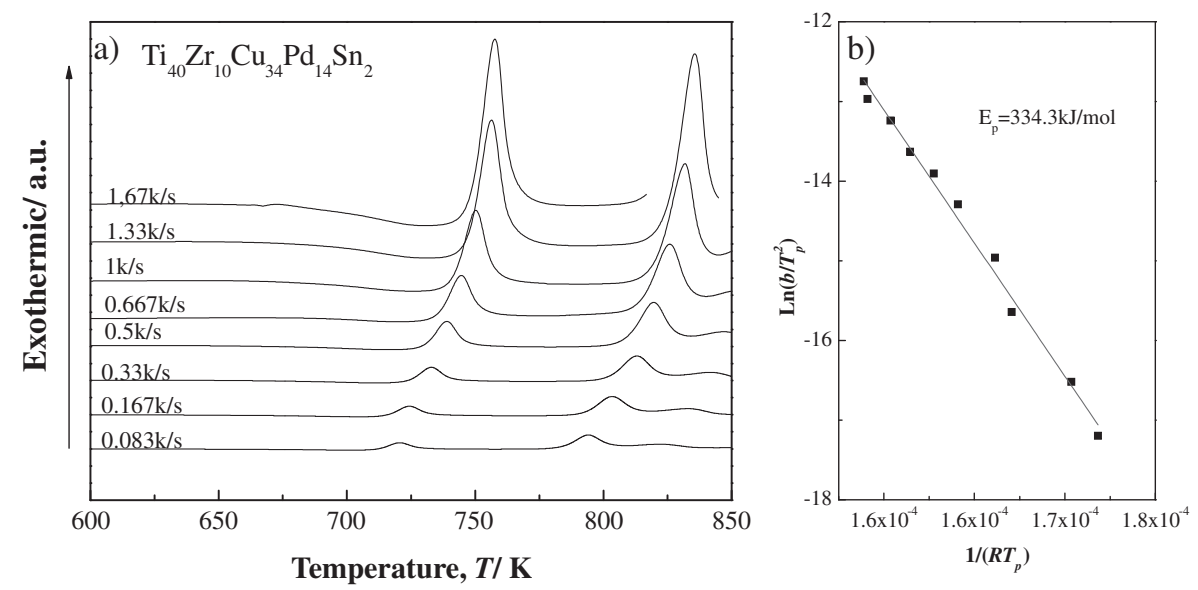

Fig. 5 DSC curves a) and Kissinger plots b) obtained after heating the $\mathrm{Ti}_{40} \mathrm{Zr}_{10} \mathrm{Cu}_{34} \mathrm{Pd}_{14} \mathrm{Sn}_{2}$ glassy alloys with different heating rates.

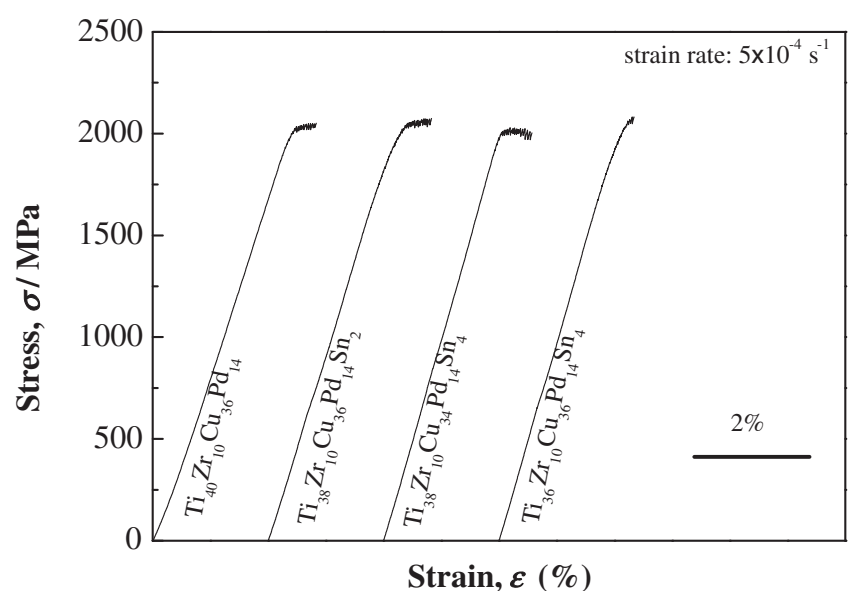

Fig. 6 Stress-strain curves of TiZrCuPdSn bulk glassy alloys.

the exclusion of $\mathrm{Sn}^{27}$ ) This process is an extra step compared with the glassy alloy without Sn. It would decrease both the nucleation and growth kinetics. Therefore, the thermal stability is improved.

Figure 6 shows the compressive stress-strain curves of TiZrCuPdSn bulk glassy alloys. With addition of $2-4 \% \mathrm{Sn}$, the compressive strength of bulk glassy alloys has no significant change and ranges from 2000-2050 MPa. However, the plastic deformation behavior is different. According to our previous work, the substitute of $\mathrm{Cu}$ by $2 \% \mathrm{Sn}$ can improve the plasticity significantly due to the formation of "weak" $\mathrm{Cu}-\mathrm{Sn}$ pair. ${ }^{18)}$ However, the substitute of Ti by $2 \%$ Sn does not improve the plasticity. Even, the substitute of Ti by $4 \% \mathrm{Sn}$ would decrease the plasticity.

\section{Conclusions}

In summary, we investigated the effect of minor addition of Sn on GFA, thermal stability and mechanical property of TiZrCuPd bulk glassy alloy system. The large critical diameter of about $12 \mathrm{~mm}$ for $\mathrm{Ti}_{40} \mathrm{Zr}_{10} \mathrm{Cu}_{34} \mathrm{Pd}_{14} \mathrm{Sn}_{2}$ bulk glassy alloy was reported. The $\mathrm{Ti}_{40} \mathrm{Zr}_{10} \mathrm{Cu}_{34} \mathrm{Pd}_{14} \mathrm{Sn}_{2}$ bulk glassy alloy exhibits higher activation energy for crystallization $(334.3 \mathrm{~kJ} / \mathrm{mol})$. The addition of $2-4 \%$ Sn can enlarge the supercooled liquid region, indicating good thermal stability. The TiZrCuPdSn bulk glassy alloys exhibit high compressive strength about 2000-2050 MPa.

\section{REFERENCES}

1) A. Inoue, T. Zhang and T. Masumoto: Mater. Trans. JIM 31 (1990) 177-183.

2) T. Zhang, A. Inoue and T. Masumoto: Mater. Trans. JIM 32 (1991) 1005-1010.

3) H. Kakiuchi, A. Inoue, M. Onuki, Y. Takano and T. Yamaguchi: Mater. Trans. 42 (2001) 678-681.

4) A. Inoue: Acta Mater. 48 (2000) 279-306.

5) T. Zhang, A. Inoue and T. Masumoto: Mater. Sci. Eng. A 181-182 (1994) 1423-1426.

6) A. Inoue, N. Nishiyama, K. Amiya, T. Zhang and T. Masumoto: Mater. Lett. 19 (1994) 131-135.

7) T. Zhang and A. Inoue: Mater. Trans. JIM 39 (1998) 1001-1006.

8) H. Men, S. J. Pang, A. Inoue and T. Zhang: Mater. Trans. 46 (2005) 2218-2220.

9) Y. C. Kim, W. T. Kim and D. H. Kim: Mater. Sci. Eng. A 375-377 (2004) 127-135.

10) S. L. Zhu, X. M. Wang, F. X. Qin and A. Inoue: Mater. Sci. Eng. A 459 (2007) 233-237.

11) W. H. Wang: Prog. Mater. Sci. 52 (2007) 540-596.

12) C. Ma, H. Soejima, K. Amiya, K. Nishiyama and A. Inoue: Mater. Trans. 45 (2004) 3223-3227.

13) S. Zhu, X. Wang, F. Qin and A. Inoue: Mater. Trans. 48 (2007) 163166.

14) S. L. Zhu, X. M. Wang, F. X. Qin, M. Yoshimura and A. Inoue: Intermetallics 16 (2008) 609-614.

15) F. Guo, H. J. Wang, S. J. Poon and G. J. Shiflet: Appl. Phys. Lett. 86 (2005) 091607.

16) D. V. Louzguine and A. Inoue: J. Mater. Res. 14 (1999) 4426-4430.

17) Q. S. Zhang, H. F. Zhang, Y. F. Deng, B. Z. Ding and Z. Q. Hu: Scr. Mater. 49 (2003) 273-278.

18) S. L. Zhu, X. M. Wang and A. Inoue: Intermetallics 16 (2008) 10311035 .

19) J. Kong, D. S. Xiong, Q. X. Yuan and Z. T. Ye: Trans. Nonferrous Met. Soc. China 16 (2006) s598-s602.

20) F. X. Qin, X. M. Wang, G. Q. Xie and A. Inoue: Intermetallics 16 (2008) 1026-1030.

21) A. Inoue: Mater. Trans. JIM 36 (1995) 866-875.

22) Z. P. Lu and C. T. Liu: Acta Mater. 50 (2002) 3501-3512.

23) Q. J. Chen, J. Shen, H. B. Fan, J. F. Sun, Y. J. Huang and D. G. Mccartney: Chin. Phys. Lett. 22 (2005) 1736-1738.

24) R. B. Schwarz and W. L. Johnson: Phys. Rev. Lett. 51 (1983) 415-418.

25) A. L. Greer: Science 267 (1995) 1947-1953.

26) H. E. Kissinger: J. Res. Natl. Bur. Stand. Sect. A 57 (1956) 217-220.

27) C. F. Li, J. Saida, M. Matsushida and A. Inoue: Scr. Mater. 42 (2000) 923-927. 